\title{
Accessibility of Public Urban Green Spaces within the Spatial Metropolitan Network of Doha, State of Qatar
}

\author{
Heba O. TANNOUS, Research Associate, Qatar \\ Mark David MAJOR, Assistant Professor of Architecture and Urban Design, Qatar \\ Raffaello FURLAN, Assistant Professor of Architecture and Urban Design, Qatar
}

\begin{abstract}
Most people regard green spaces as a necessity to enhance the physical health and psychological well-being of residents in promoting the general health and welfare of citizens and the environment (Röbbel, 2016). In the Modern Era, the availability of green spaces has become an integral component of urban planning for sustaining the quality of life in city environments, especially since the dawn of the $20^{\text {th }}$ century. Due to globalization in rapidly-developing cities around the world, studies about green spaces are becoming an increasingly important part of the urban planning process (Mitchell and Popham, 2007). Accessibility can play an essential role in determining the location of green public facilities to maximize their usability for large populations, or otherwise limit use to a smaller community (Ottensmann and Greg, 2008). However, some public green spaces are inefficiently located or distributed in urban environments (Beatley, 2000, Gehl, 2010, Gehl and Svarre, 2013). In this paper, the accessibility of urban green spaces means the ease of reaching such locations from many origins within the urban spatial network from the macro- to the micro-scale. The inaccessibility or absence of green spaces in some urban areas is a notable consequence of rapid urbanization in many cities around the world. It is especially noticeable in the capital city of Doha in the State of Qatar, where rapid urban expansion and globalization has had a significant impact on the quality and quantity of green spaces available (Salama and Wiedmann, 2013a). The paper utilizes the network analysis techniques of space syntax to objectively investigate the accessibility of urban green parks and promenades in the metropolitan region of Doha (Penn et al., 1998, Hillier et al., 1993, Hillier and Hanson, 1984). At the heart of the paper is the question, does the size and location of urban green spaces follow a discernible spatial logic in terms of accessibility, linked to the design intent of public planning policies? Some findings in the paper indicate there is distinctive spatial and social logic to the physical and spatial characteristics of urban green spaces above a certain size in terms of metric area. In contrast, these characteristics in smaller urban green spaces tend to be more random, primarily due to issues of land availability and amenity provision in private developments. We conclude by discussing the potential implications of the study for public planning policy about green urbanism in the State of Qatar and other rapidly urbanizing cities around the world.
\end{abstract}

\section{Keywords}

Accessibility, Green Spaces, Network Science, Planning Policy, Urban 


\section{Introduction}

Many of the major cities in the developing world share common problems arising from rapid development and population growth. It is a result of changes in land use to cater to the growing need for industrial, commercial, and residential development. Such growth is further intensified in the case of the capital city of Doha in the State of Qatar, driven by rapid economic development during the last two decades. There are significant government efforts to transform Doha physically and economically from its fishing and pearling village origins of the early $20^{\text {th }}$ century into a modern diversified economy with global aspirations in the $21^{\text {st }}$ century. The population of Qatar is over 2.8 million inhabitants in 2020 with a projected increase of 1 million within the next 20 years based on the most recent United Nations data. Over half of the population is concentrated in Metropolitan Doha (Ministry of Development Planning and Statistics, 2020).

Although the natural gas and petroleum resources are immense, the government is aiming economic diversification plans at the tourism, education, sports, and other service-related industries (Dumper and Stanley, 2007). Doha is currently constructing several mega-projects, stadiums, and the associated facilities necessary for hosting the FIFA World Cup in 2022. Other projects include the Qatar Rail metropolitan public rail transit system, Lusail City masterplan, Hamad Port, Green Parks, and expanded road infrastructure network (Figure 1). With many of these projects along the coastline, large sections have been artificially modified involving reclaimed land as the original shoreline was located further inland (Figure 2a).
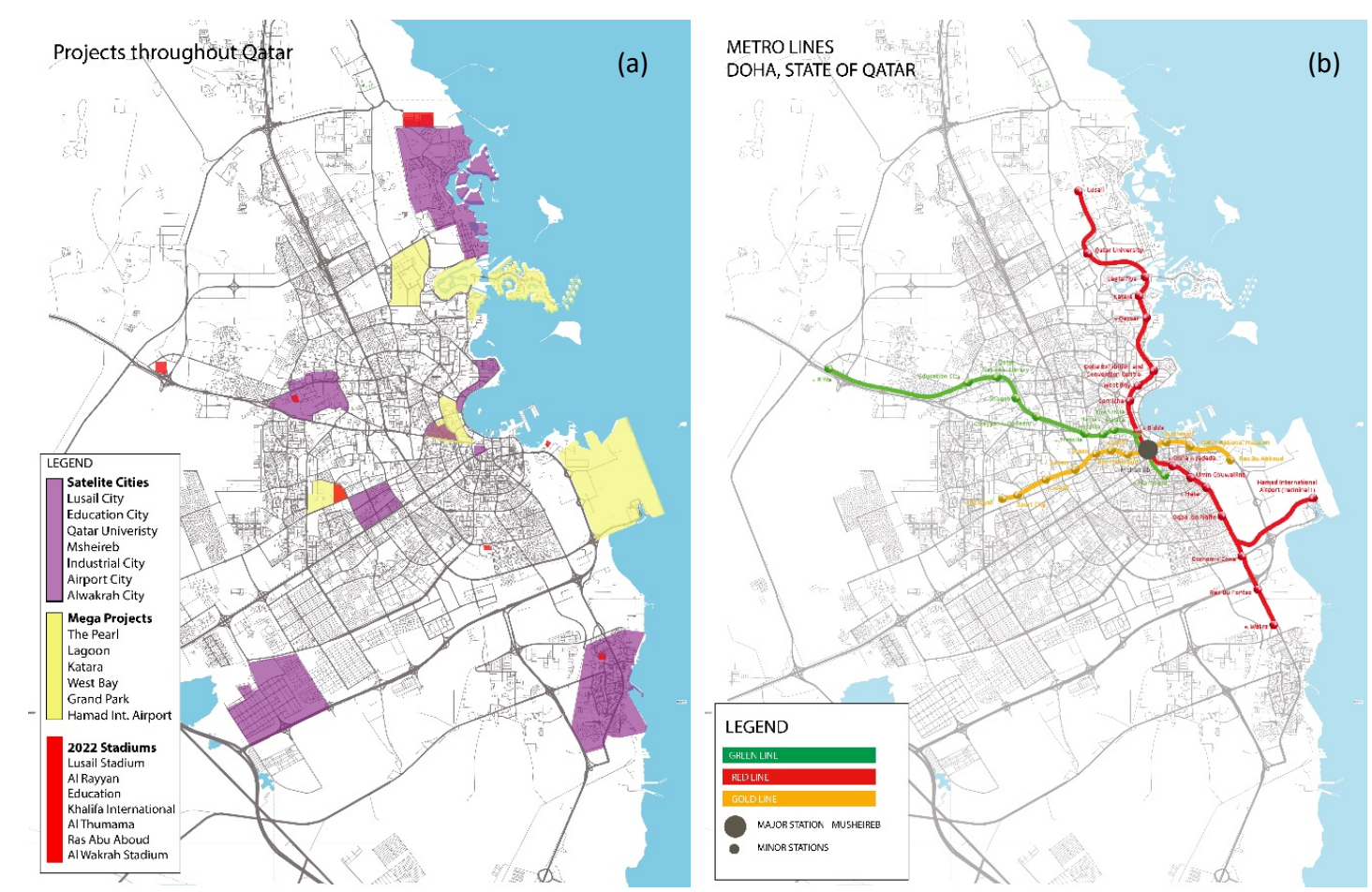

Figure 1. Maps of Doha highlighting (a) satellite cities, mega-projects, and FIFA 2022 Stadium, and (b) Qatar Rail main metro lines and stations. (Source: Authors/Qatar Rail).

Driven by this rapid growth, Qatar has one of the fastest-growing populations in the Arab world with the population increasing by approximately 30\% between 2003 and 2012 (Tannous, 2020) (Figure 2b). The majority of this population ( $\sim 0 \%$ ) live in the capital city of Doha. Under these circumstances, the 
provision of green spaces does not become a high priority compared to other necessities such as housing, industrial, and infrastructure (Hashem, 2015, Tan et al., 2013). The overall urban planning strategy of simultaneous densification and land consumption is a major contributory factor for environmental deterioration in the country (Salama and Wiedmann, 2013a).
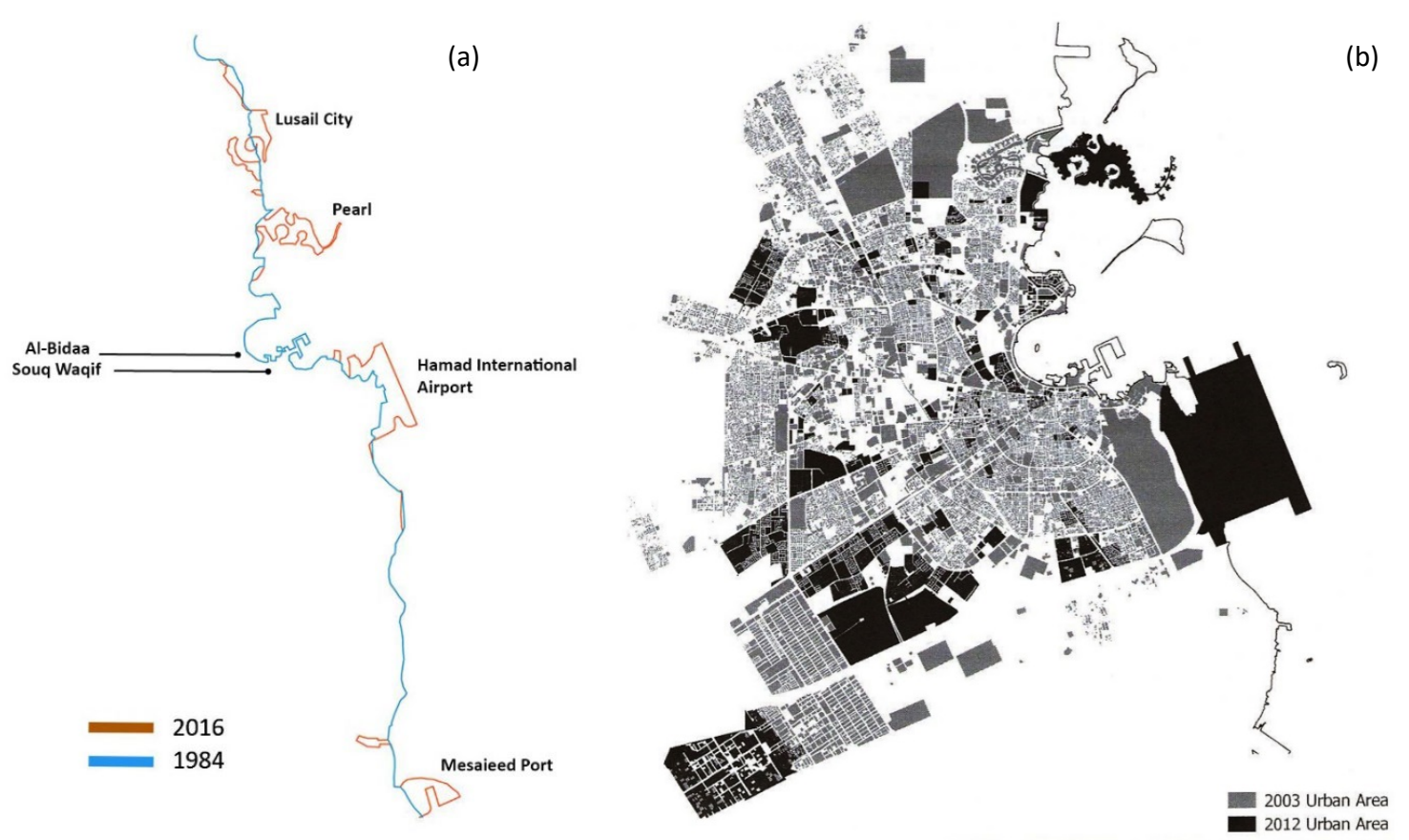

Figure 2. (a) Changes in Doha's shoreline through 1984-2016; (b) Urban Land in Doha between 2003 through 2012 (Source: Authors/(Salama and Wiedmann, 2013b).

The State of Qatar government developed the Qatar National Vision 2030 (QNV) to address the lack of a national planning framework. It aims to guide the development strategies across all sectors of the country. In the light of the QNV, the Ministry of Municipality and Urban Planning (MMUP) and Ministry and Municipality of Environment (MME) has adopted a national framework for urban development with a master plan under the Qatar National Development Framework (QNDF) (Ministry of Municipality \& Environment, 2016a). One of the main principles for guiding development is the appropriation of urban design and planning strategies to ensure sustainable growth and preservation of land for public green spaces (Figure 3).

In the case of Doha, green spaces are very resource-demanding due to the dry and hot desert climate. Due to the extreme heat and lack of rain, most irrigation water comes from desalination plants that are expensive to run (Hashem, 2015). These public green spaces also require high investment in labor forces for maintenance and sophisticated irrigation systems used in cities within a desert climate. Given these issues, the Public Parks Department of the MME has successfully implemented a field experiment intending to minimize water used in irrigation. This is an initiative to help increase the green areas in different parts of the country (Ministry of Municipality \& Environment, 2016b). 

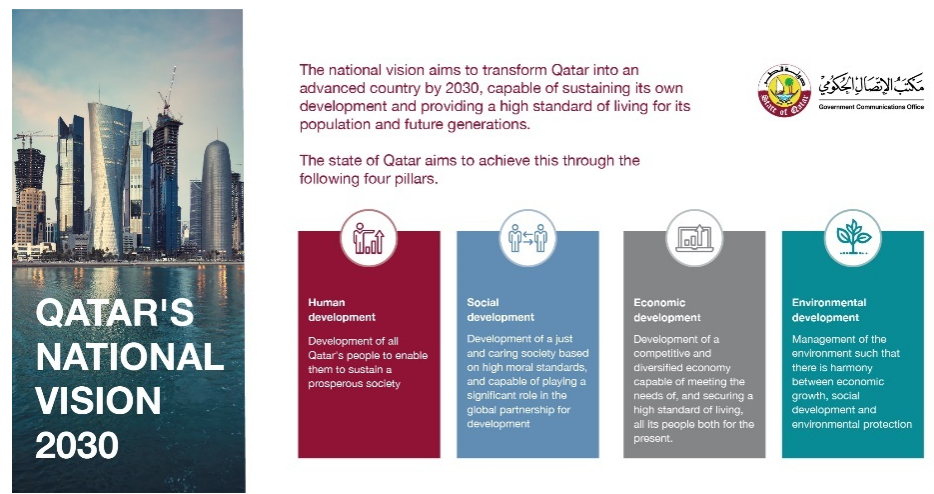

Figure 3. Key components of Qatar National Vision 2030 (Source: (General Secretariat for Development Planning, 2008).

\section{Green Urbanism}

Green Urbanism is interdisciplinary by definition. It involves collaboration between the fields of landscape, architecture, engineering, urban planning, transport planning, ecology, psychology, sociology, economy, and many other specialists. Green Urbanism is an approach that adopts different disciplinary perspectives in promoting sustainability as its primary objective. It highlights the role of cities in reducing greenhouse gas emissions based on fossil fuels and the preservation of the natural systems of the environment. The principles of Green Urbanism form the basis for a conceptual framework, which allows for the development and transformation of existing neighborhoods and communities in cities. It offers a way to re-think about the way we design and build our future urban settlements. A key goal of Green Urbanism involves retrofitting existing built environments to operate within ecological limits through the promotion of compact development utilizing different modes of transportation (Beatley, 2000). We can summarize the principles of Green Urbanism into four categories: urban planning and transport, energy and materials, socio-cultural features, and water and biodiversity (Lehmann, 2014). Lehman offers perhaps the best outline of these general principles for Green Urbanism and their inter-relationship (Figure 4).

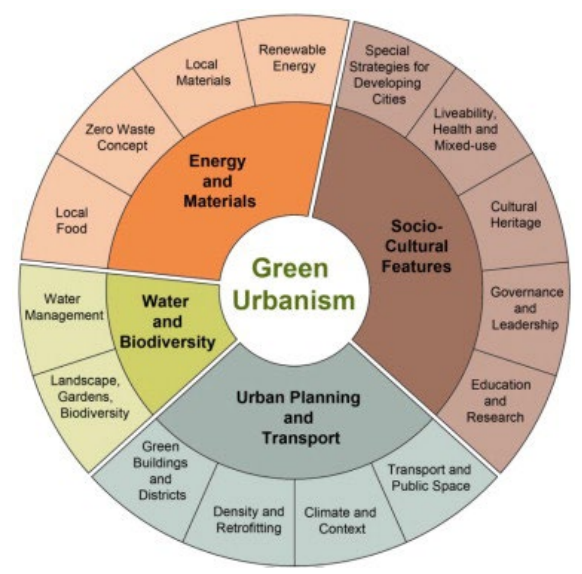

Figure 4. 15 principles and their inter-relationship in Green Urbanism (Lehmann, 2014).

\section{Urban Green Spaces}

Public green spaces are a component of 'green infrastructure,' which provides for many social, physical, and environmental benefits including urban heat reduction (Anguluri and Narayanan, 2017). They can serve as recreational areas for residences and enhance the environmental quality of neighborhoods. The 
availability and accessibility of green spaces are a significant contributor for human well-being in urban cities (Amano and Butt, 2018). With a set of a range of policies on urban green spaces, the European Environment Agency recommends that citizens should have access to green spaces within 15 minutes walking distance, i.e., approximately $2 \mathrm{~km}$ (Stanners and Bourdeau, 1995). Other studies in planning and environmental disciplines highlight the social and ecological benefits of urban green space depending on their size and accessibility (Box and Harrison, 1993, Harrison et al., 1995). In addition to user needs and the quality of green spaces, there is a large body of research focusing on the role of the built environment on human behavior in public open spaces over the last half-century (Jacobs, 1961, Whyte, 1980, Hillier, 1996b, Gehl, 2010, Campos, 1999, Gehl, 2011). Many argue additional benefits like improving air quality, general health and well-being of the citizens, and enhancing the urban setting of cities (Lee et al., 2015, Mitchell and Popham, 2007). Therefore, just like any other land use, the way these green spaces are located and distributed is essential. Selecting inappropriate locations for public green spaces can make them less accessible to the public, leading to underutilized or sometimes neglected spaces. At worst, these spaces become abused or exploited for illicit and criminal behaviors (Hillier, 1996a).

The smart allocation of easily accessible and equally-distributed green spaces can serve as a healthpromoting setting for all members of the urban community. Sustainable and accessible public green spaces are necessary to provide a higher quality of life in cities. Public green spaces are generally any outdoor space providing green vegetation for active or passive uses accessible to the general public. Such areas include formal parks, community gardens, informal green spaces/landscapes, playgrounds, and plazas but not spaces that can be characterized as exclusively landscape medians for only visual appearance, i.e., curb appeal.

\section{Accessibility of Urban Green Spaces}

Most studies about the accessibility of urban green spaces are based on metric distance. However, topological distance in space syntax terms is also a potentially important, often overlooked factor for the location of public green spaces (Koohsari et al., 2014). Instead of mere location based only on metric distance, understanding and quantifying the distribution and accessibility of public green spaces based on the configurational measurements of space syntax using axial analysis might prove fruitful for promoting the physical and social functioning of public green spaces in a city.

This research paper aims to examine the accessibility of public urban green spaces relative to metric size in the area of Metropolitan Doha, Qatar. The research draws on a previous study by the authors examining the accessibility of public green spaces in Doha in the year 2013 (Tannous et al., Forthcoming). Subsequently, this study identifies and incorporates four (4) parks and three (3) promenades that were not previously listed by the MME as public amenities at the time of the previous research study (Figure 5a). The classification of these different types of public green spaces in this research study relies on the metric area and service radius. It is divided into seven (7) types: mini-neighborhood, neighborhood, local, community, regional, metropolitan/national, and promenades. Promenades are the only classification not based on metric area but due to their location adjacent to the coastline of the Arabian/Persian Gulf (Figure 5b). In addition to these promenades, there are also many parks located in the vicinity of the coast due to the importance of the Arabian/Persian Gulf for the city of Doha. However, the quantity of green space is not necessarily the defining characteristic of promenades as public amenities. Sports fields such as football pitches serving as support facilities for World Cup 2022 are not included in this analysis, especially if the MME does not list them as official parks.

The research reviews the current availability and accessibility of thirty-three (33) public parks and promenades based on high-resolution aerial photos from 2013-2019, supplemented by the use of an 
MME index listing official parks in the city of Doha. This study continues and expands on the analysis of these public green spaces in the urban spatial network of Metropolitan Doha used in the earlier study (Tannous et al., Forthcoming). The underlying basis for quantifying the accessibility of public green spaces using space syntax is the theory of natural movement. This theory states that movement patterns in cities arise naturally from the way the street network organizes the simplest routes to and from all locations involving the fewest changes of direction in the network before accounting for the location of attractors or generators of that movement such as specific land uses (Hillier et al., 1993, Penn et al., 1998). Based on the analysis and findings of this study, the paper argues for the existence of a spatial and social logic to the public green spaces of Metropolitan Doha, especially above a certain size. The paper concludes with some suggestions for the future planning and expansion of some public green spaces in Metropolitan Doha.
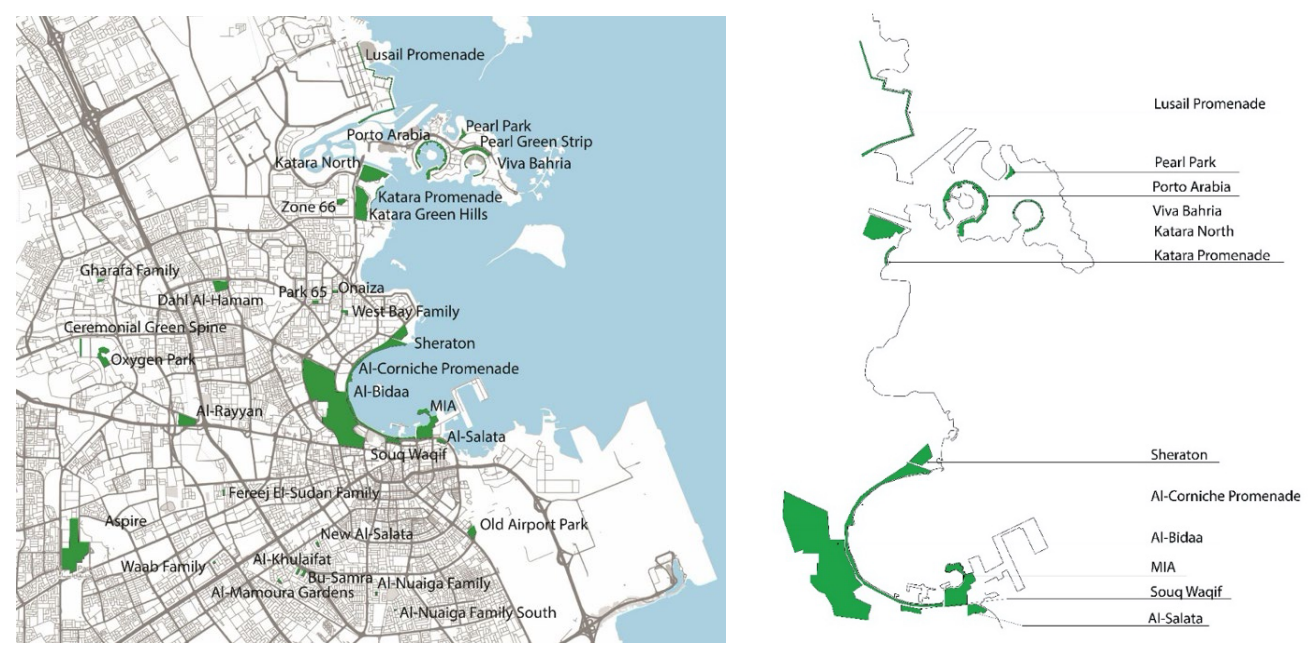

Figure 5. (a) The studied public parks and promenades on the map of Metropolitan Doha; b) promenades and parks running parallel to the coastline of Doha (Source: Authors).

\section{Space syntax}

Space syntax has been used in a wide range of research projects to explain human behaviors and predict patterns of movement from the point of view of spatial configuration (Hillier, 1996a). Some of this research examined the morphological structure of buildings (Peponis et al., 1990), sociocultural implications of different plans (Hanson, 1989), urban renewal (Miller, 1989), predictions of spatial patterns of crime in urban areas (Hillier et al., 1989), and, frequently, movement patterns in urban settings (Hillier and Hanson, 1984, Hillier et al., 1983, Hillier et al., 1987, Hillier et al., 1989, Peponis et al., 1989). Space syntax researchers have also found significant correlations between spatial configuration and empirical observations of pedestrian and vehicular movement levels (Hillier, 1996b, Hillier et al., 1993, Penn et al., 1998). Major development projects around the world extensively applied space syntax as a design and planning tool over the last thirty years (Major, 2018). In its simplest formation, space syntax allows us to better identify and understand human behavior in the urban environment in terms of movement, occupation, and use.

There are many previous research-based studies of urban green spaces based on statistical evaluation of demographics and design characteristics, location-based attraction modeling, or user surveys to understand some attributes of accessibility (Ottensmann and Greg, 2008, Strauss and Miranda-Moreno, 2013, Sahebgharani et al., 2019). Other studies focus on localized issues such as human thermal comfort (Indraganti and Boussaa, 2018), quality and status of green parks, or the impact of road network expansion on the urban landscape (Wenbo et al., 2017). However, there is a lack of quantitative research 
on the subject in the GCC region. The study utilizes space syntax for the quantitative measurements of accessibility within the urban spatial network. It uses a distance concept (relativized mean depth) measured in steps or changes of direction called topological distance (Hillier and Hanson, 1984). Space syntax models the spatial configurations of the urban space by using a connectivity graph representation. It highlights the most accessible (or integrated) spaces which tend to obtain higher levels of movement and activities, and the less accessible (or segregated) spaces tend to experience less use most of the time.

The term accessibility has a broad meaning in both green urbanism and space syntax. In this research study, accessibility refers to different ranges of integration from across the urban spatial network of Metropolitan Doha to the perimeter streets providing access points to the public green spaces selected for the study. In this sense, accessibility is an essential factor for consideration to provide a strategic plan for public green spaces within their broader neighborhood, regional, and metropolitan network. However, in this most recent version of the study, we begin to layer metric distance into the analysis based on the drawing of pedestrian sheds within a radii of $400 \mathrm{~m}$ from recently-opened Doha Metro stations in relation to the case study parks, green spaces, and promenades.

\section{Measurements and Techniques}

Configurational measures offer a scientific basis to implicate or dismiss the designed spatial network as a factor in social, functional, and/or cultural outputs. Space syntax software also incorporates metric parameters such as the length of streets/street segments and the plan area/perimeter surface area of visual fields. Over four decades, researchers have developed a diverse number of configurational and metric measures using space syntax. Some are more useful than others, and sometimes it can take years of testing to confirm or refute their usefulness. It can be overwhelming for those unfamiliar with space syntax. Generally, the most useful are:

Connectivity is a simple measure of how many other spaces does a single space immediately connect to within the network.

Integration is the relativized mean depth of a space in relation to all other spaces in a network based on changes of direction using connectivity (see above). It represents how integrated/shallow or segregated/deep is a space within a spatial network. It demonstrates the pattern of 'to-movement' for those spaces most likely used for journeys from anywhere to everywhere else in the spatial network. Researchers can set the radii of integration measures based on specified parameters such as global integration (radius $=\mathrm{n}$ ) and local integration (radius=3).

Local integration is relativized mean depth of a space in relation to all other spaces in a network based on three changes of direction, which highlights the more immediate catchment area of a single space within the network. In effect, the justified topological graph underlying the measure is 'cut' off for every space more than three changes of anywhere from the origin space. Most usually, local integration is strongly related to connectivity (see above) because they measure the more immediate characteristics of space in the network. In the real world, the simplest way to understand local integration is if a person imagines themselves standing in the middle of an intersection of two or more spaces, looks down both spaces in all directions to see all other spaces immediately connected to those spaces defining the intersection, and then repeated that process for all the other intersections they can see from the first intersection. In larger spatial systems such as cities, it is often useful to limit the radius of integration based on relativized mean depth from the most globally integrated space in the spatial network because it reduces, though not necessarily eliminates completely, 'edge effect,' i.e., spaces at the edges of the spatial network tend towards segregation merely because of their location at the edge. 
Finally, researchers can also set the radii of various configurational measurements based on metric parameters using the average distance to the center of each segment as defined by the midpoint between two separate connections such as 500 meters $(\mathrm{m}), 1000 \mathrm{~m}$, or $5000 \mathrm{~m}$. Despite incorporating metric measures, researchers consistently find that the correlation with configurational measures tends to be more significant for understanding the 'social logic of space' than metric ones (Hillier and Vaughan, 2007).

\section{Research methodology}

The main research study methodology consists of two main phases:

Identifies and locates official public parks and promenades in mapping for the case studies of the research study.

Obtains and analyzes the quantitative measurements of different levels of integration relative to the metric area of all perimeter streets providing points of access to the studied public green spaces to all other axial lines in the urban spatial network of Metropolitan Doha. We utilize three parameters of integration, i.e., global (radius=n), local (radius=3), and mean depth based on the most integrated streets in Doha (radius=8).

Table 1. Classification and categories of the studied parks and promenades according to their metric areas and service radius.

\begin{tabular}{|l|c|c|l|}
\hline \multicolumn{1}{|c|}{ Type } & Amount & Area & \multicolumn{1}{c|}{ Service Radius } \\
\hline Mini-neighborhood (MN) & 10 & $<4$ & $1 / 4$ miles radius \\
\hline Neighborhood (N) & 7 & $4-10$ & 1 mile radius \\
\hline Local (L) & 2 & $10-20$ & $1-2$ miles radius \\
\hline Community (C) & 4 & $20-50$ & $2-5$ miles radius \\
\hline Regional (R) & 3 & $\begin{array}{c}50- \\
150\end{array}$ & 5+ miles radius \\
\hline Metropolitan/national (M) & 2 & $>150$ & $\begin{array}{l}\text { Entire metropolitan region and/or serve } \\
\text { as an urban setting on a national basis }\end{array}$ \\
\hline Promenade (P) & 5 & & No specified area \\
\hline TOTAL & $\mathbf{3 3}$ & & \\
\hline
\end{tabular}

The research study focuses on the metropolitan region of Doha, Qatar. We classify and organize the case study parks and promenades according to metric area and size parameters into the following categories (Table 1 and Figure 6):

- Mini-neighborhoods ( $\mathrm{N}$ ) below 4 acres in size with a service radius of approximately $1 / 4$ miles.

- Neighborhood (N) ranging in size between 4-10 acres with a service radius of 1 mile.

- Local (L) ranging in size between 10-20 acres serving 1-2 miles radius.

- Community (C) ranging in size between 20-50 acres with a service radius of 2-5 miles.

- Regional (R) ranging in size between 50-150 acres with a service radius of over 5 miles.

- Metropolitan/national (M) with the metric area over 150 acres serving the metropolitan region.

- Promenades are identified and located due to their location along the coast of Doha. 


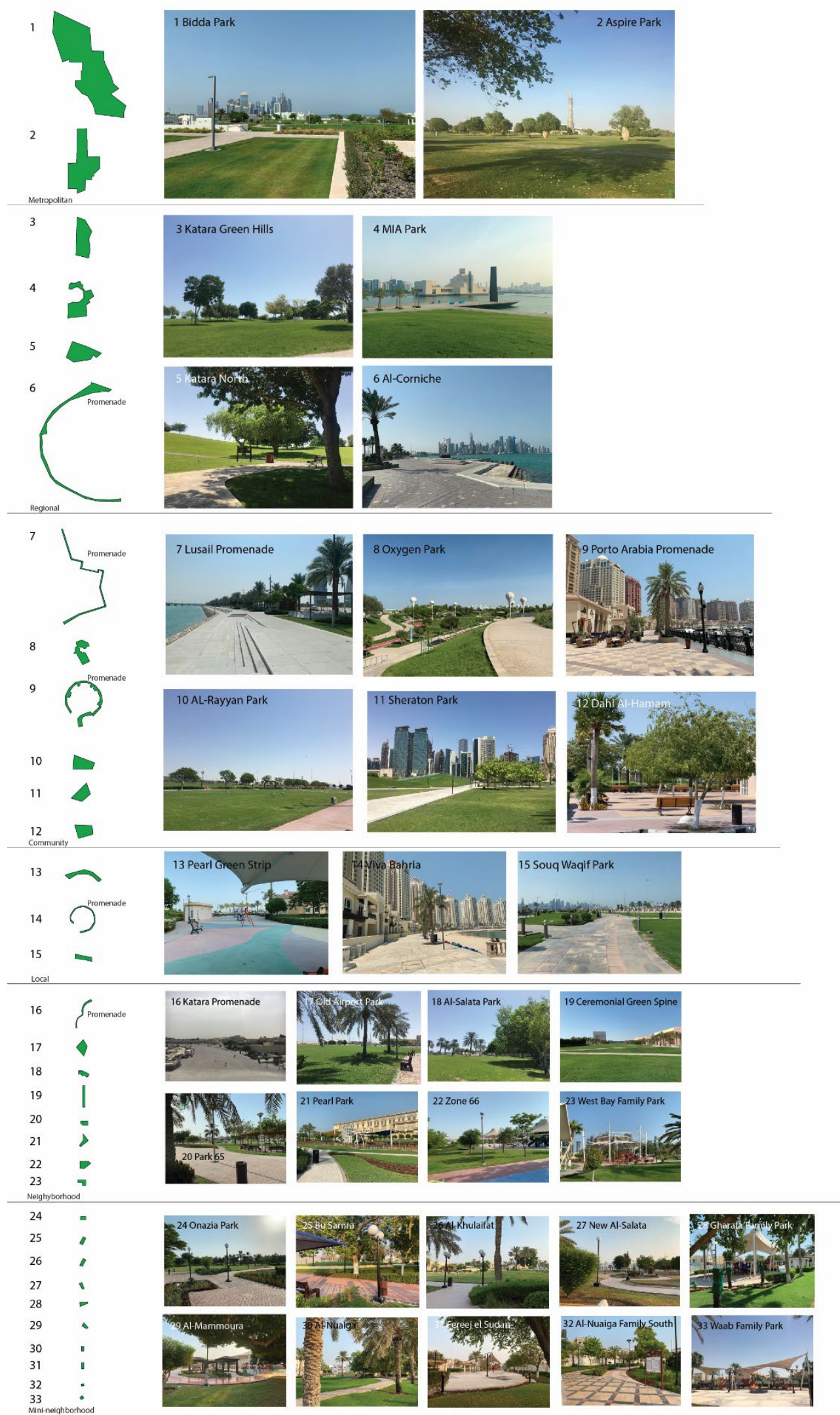

Figure 6. Case study green spaces in descending order (in terms of metric area) within Metropolitan Doha (Source: Authors). 
The axial map in this study stretches from Lusail in the north to Al-Wakrah to the south and from the Arabian/Persian Gulf in the east to the Orbital Highway to the west (Figure 7a). Researchers constructed the 2019 space syntax model of Metropolitan Doha based on a collection of high-resolution satellite images in 2019, updated against the initial modeling based on a 2013 MME map showing building footprints at a scale of 1:400 and various satellite images from 2013-2018. The axial map consists of over 24,200 streets covering an area of over $1,000 \mathrm{~km}^{2}$. Researchers located the streets defining the perimeter of the 33 public parks and promenades of the study in the axial map. The analysis of different degrees of accessibility was based on the average value of all perimeter streets, as well as relative to the metric area of the urban green space itself.

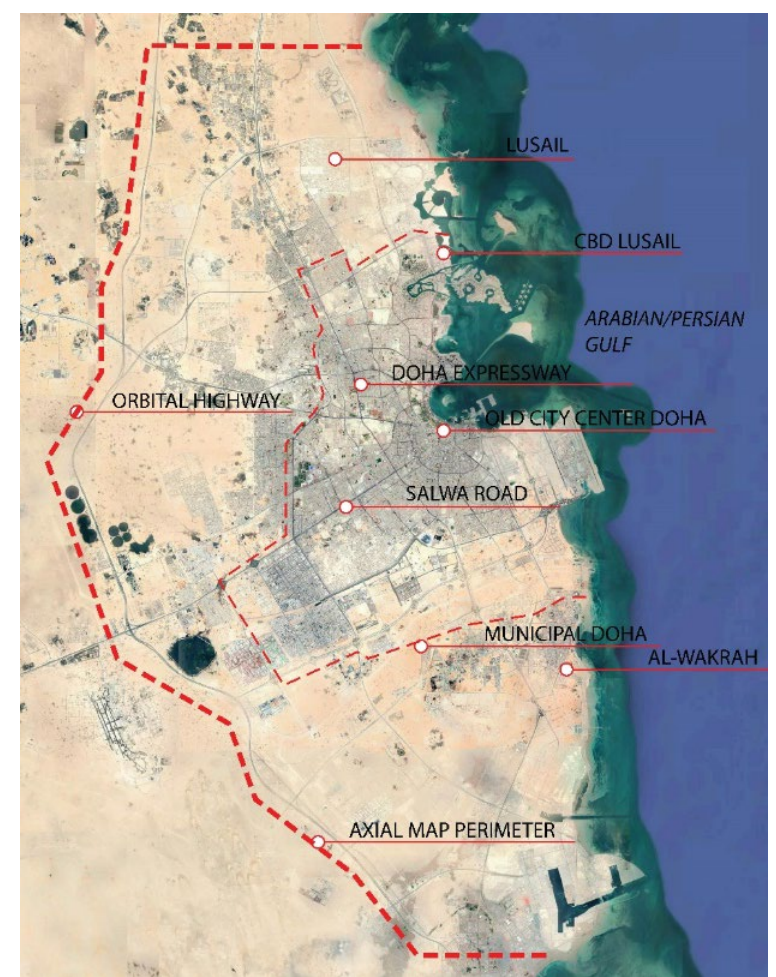

Figure 7. The area of study for the axial map referred to as Metropolitan Doha (Source: Authors).

\section{Findings}

As explained in the previous section, this research study illustrates the levels of accessibility of 33 public parks and promenades. The total area of these green spaces is approximately 1,132 acres or about 1 acre every 1,200 residents in Metropolitan Doha. According to the National Recreation and Parks Association (NRPA), the typical park level of services is 9.9 acres per 1,000 residents across different parks and recreation agencies of the United States. It suggests that the current levels of service for public parks and promenades in Metropolitan Doha are nearly 12 times lower than that found in the USA in general. All the promenades and many of the parks locate immediately adjacent or relatively near to the Persian/Arabian Gulf coastline in the city. These green spaces include all the parks and promenades at The Pearl, Sheraton, Al-Corniche, Al-Bidda, and MIA from north to south of the coastline. Others consist of smaller parks serving their immediate surrounding neighborhoods, such as the Al-Gharafa, AlKhulaifat, and Al-Nuaiga parks.

The spatial structure of the metropolitan region is characterized by the ortho-radial grid based on long radial routes (e.g., Salwa Road to the southwest, and Al Rayyan Road to the west) from the old city center 
of Doha near the coastline and a successive series of ring roads (A-G) radiating outward from Doha Bay to the metropolitan edges and the new Orbital Highway (Ring Road G). A few research studies elaborate on the well-defined spatial logic of Doha at the macro- and micro-scale of its metropolitan region using space syntax (Tannous, 2020, Tannous and Major, 2020, Mirincheva, 2015). An aim of this research study is establishing the spatial parameters of the green parks and promenades by locating them in the space syntax model of Metropolitan Doha based on their streets defining their perimeter based on an average of each accessibility measure. It provides a common representative measurement for each park and promenade within its local and larger metropolitan context (Table $\mathbf{2}$ and Figure 7).

Table 2. The public parks, promenades, and green spaces from largest to smallest for metric area showing (from left to right): name of the green space, type classification, region within the city, area in acres and $\mathrm{m} 2$, and the average global integration (Rn), local integration (R3), and integration based on mean depth from most integrated street (R8).

\begin{tabular}{|c|c|c|c|c|c|c|c|c|}
\hline & Park Name & Type & Region & Area Acre & Area $\mathbf{m} 2$ & $\begin{array}{l}\text { Global } \\
\text { rad=n }\end{array}$ & $\begin{array}{c}\text { Local } \\
\text { Integration } \\
\text { rad=3 }\end{array}$ & $\begin{array}{c}\text { Integration } \\
\mathrm{rad}=8\end{array}$ \\
\hline 1 & Bidda & $M$ & East & 426.0 & $1,723,962$ & 1.282 & 2.578 & 1.668 \\
\hline 2 & Asipire & $M$ & South West & 185.7 & 751,502 & 1.496 & 3.256 & 2.007 \\
\hline 3 & Katara Green Hills & $R$ & East & 74.3 & 300,682 & 0.972 & 2.199 & 1.433 \\
\hline 4 & MIA & $\mathrm{R}$ & East & 70.5 & 285,304 & 0.939 & 1.973 & 1.223 \\
\hline 5 & Katara North & $R$ & North & 65.4 & 264,665 & 0.877 & 1.807 & 1.247 \\
\hline 6 & Al-Corniche & $\mathrm{P}$ & East & 57.2 & 231,480 & 1.114 & 2.179 & 1.480 \\
\hline 7 & Lusaail & $P$ & North & 33.5 & 135,570 & 0.976 & 1.714 & 1.231 \\
\hline 8 & Oxygen & C & West & 31.3 & 126,667 & 0.989 & 1.500 & 1.115 \\
\hline 9 & Porto Arabia & $\mathrm{P}$ & North & 28.0 & 113,312 & 0.552 & 1.083 & 0.826 \\
\hline 10 & Al-Rayyan & C & West & 24.2 & 97,934 & 1.488 & 2.941 & 1.877 \\
\hline 11 & Sheraton & C & East & 22.9 & 92,673 & 0.990 & 2.292 & 1.413 \\
\hline 12 & Dahl Al-Hamam & C & North & 21.6 & 87,412 & 1.275 & 2.978 & 1.802 \\
\hline 13 & Pearl Green Strip & $\mathrm{L}$ & North & 19.3 & 78,104 & 0.605 & 1.599 & 1.006 \\
\hline 14 & Viva Bahria & $\mathrm{P}$ & North & 10.9 & 44,111 & 0.552 & 1.083 & 0.826 \\
\hline 15 & Souq Waqif & $\mathrm{L}$ & East & 10.1 & 40,873 & 1.259 & 3.087 & 1.704 \\
\hline 16 & Katara Promenade & $P$ & East & 8.2 & 33,265 & 0.758 & 1.389 & 0.959 \\
\hline 17 & Old Airport Park & $\mathrm{N}$ & South & 6.8 & 27,519 & 1.202 & 3.105 & 1.787 \\
\hline 18 & Al-Salata & $\mathrm{N}$ & South East & 6.2 & 25,091 & 1.106 & 2.895 & 1.577 \\
\hline 19 & Ceremonial Green Spine & $\mathrm{N}$ & West & 5.9 & 23,876 & 1.467 & 2.847 & 1.599 \\
\hline 20 & Park 65 & $\mathrm{~N}$ & North & 5.5 & 22,258 & 1.019 & 2.238 & 1.487 \\
\hline 21 & Pearl Park & $\mathrm{N}$ & North & 5.1 & 20,639 & 0.647 & 1.776 & 1.090 \\
\hline 22 & Zone 66 & $\mathrm{~N}$ & North & 4.2 & 16,997 & 0.924 & 2.216 & 1.345 \\
\hline 23 & West Bay Family Park & $\mathrm{N}$ & North & 4.0 & 16,187 & 1.071 & 2.339 & 1.532 \\
\hline 24 & Onaiza Park & $\mathrm{MN}$ & North & 2.4 & 9,712 & 0.846 & 1.200 & 1.175 \\
\hline 25 & Bu Samra & $\mathrm{MN}$ & South & 2.4 & 9,712 & 1.522 & 2.624 & 1.951 \\
\hline 26 & Al-Khulaifat & $\mathrm{MN}$ & South & 2.3 & 9,308 & 1.100 & 0.887 & 1.294 \\
\hline 27 & New Al Salata & $\mathrm{MN}$ & South & 1.8 & 7,284 & 1.115 & 1.295 & 1.409 \\
\hline 28 & Gharafa Family & $\mathrm{MN}$ & North West & 1.7 & 6,880 & 1.032 & 2.491 & 1.389 \\
\hline 29 & Al-Mamoura Garden & $\mathrm{MN}$ & South & 1.7 & 6,880 & 1.272 & 2.100 & 1.685 \\
\hline 30 & Al-Nuaiga family & $\mathrm{MN}$ & South & 1.0 & 4,047 & 1.028 & 1.489 & 1.370 \\
\hline 31 & Fereej Al Sudan Family & $\mathrm{MN}$ & South & 1.0 & 4,047 & 1.389 & 2.603 & 1.845 \\
\hline 32 & Al-Nuaiga family (South) & $\mathrm{MN}$ & South & 0.9 & 3,642 & 1.139 & 2.503 & 1.629 \\
\hline \multirow[t]{3}{*}{33} & Waab Park & $\mathrm{MN}$ & South & 0.8 & 3,076 & 1.184 & 1.484 & 1.595 \\
\hline & TOTAL & & & 1142.8 & $4,621,595$ & & & \\
\hline & AVERAGE & & & 34.6 & 144,425 & 1.066 & 2.114 & 1.442 \\
\hline
\end{tabular}

* Because of its size, Katara Promenade falls within the neighborhood range, but there are beach extensions and under-construction continuation of the promenade. 

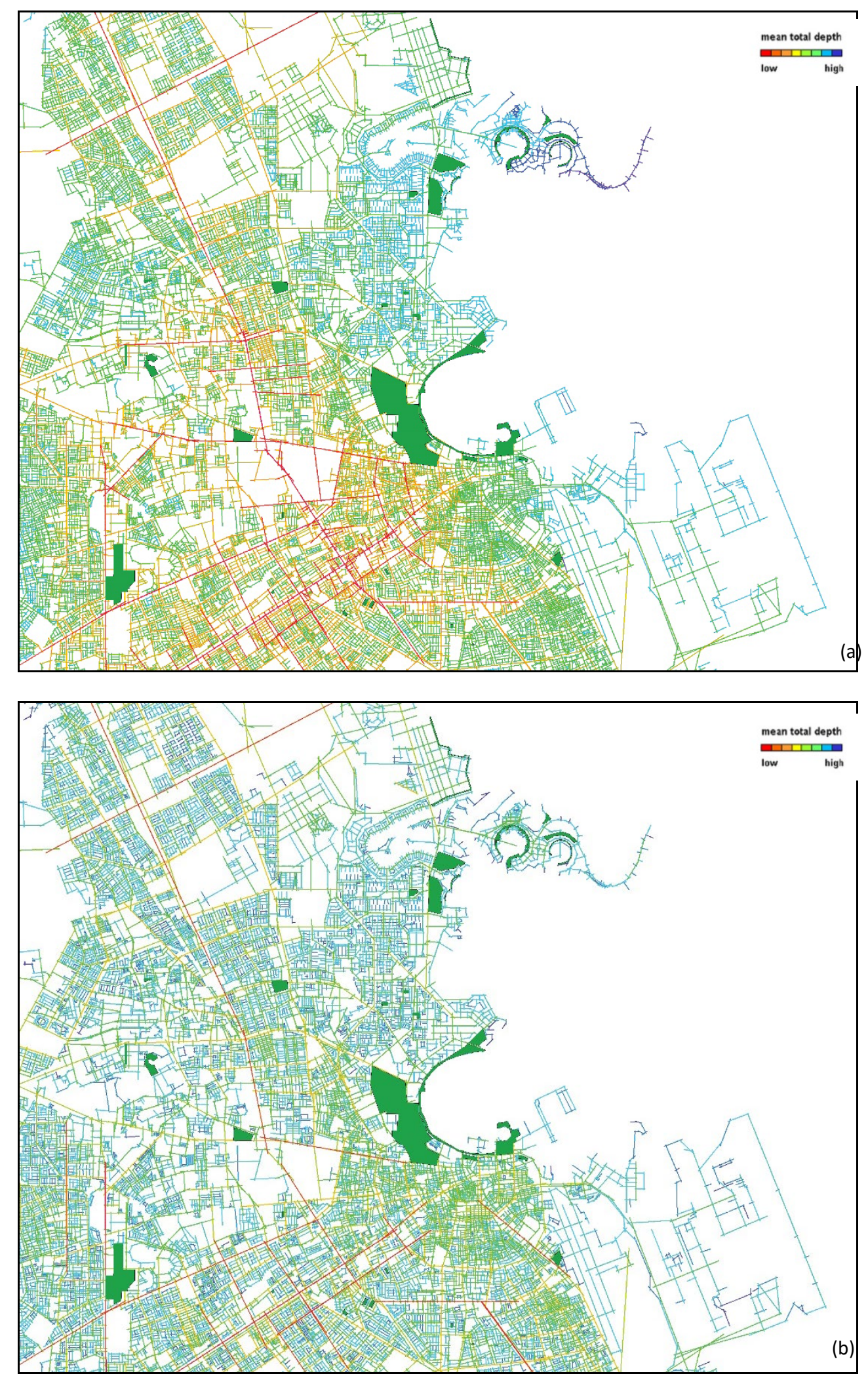


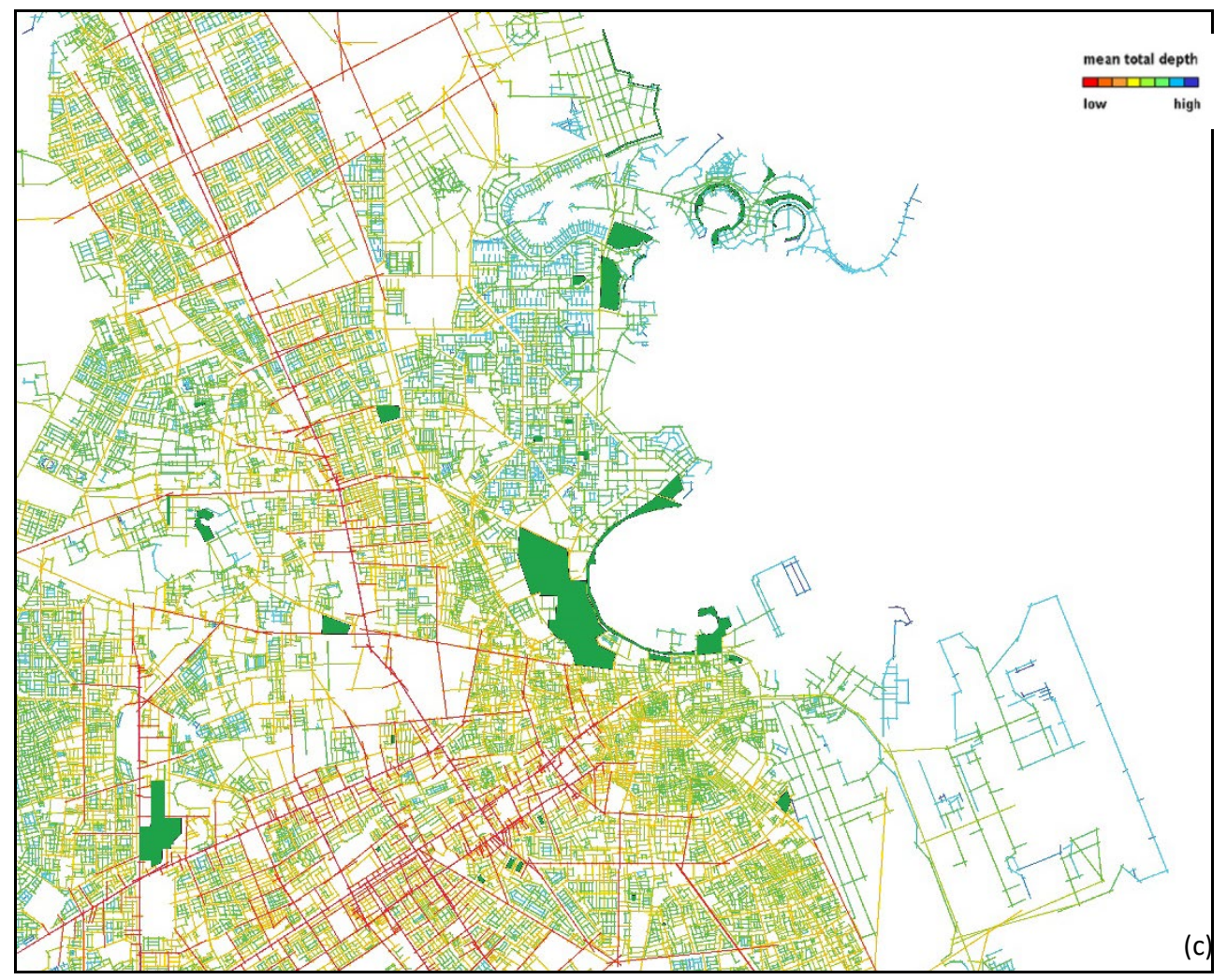

Figure 8. Space syntax model of the urban spatial network Metropolitan Doha showing the pattern of accessibility of the studies green spaces for (a) global integration, (b) local integration, and (c) integration (radius $=8$ ).

The global integration core, as previously identified in the earlier research, has shifted southwest to the D-ring Doha Expressway and the intersection between Al-Waab Road and Al-Rayyan Road. With the majority of the regional and metropolitan parks located along the coast, they are relatively locally segregated. Aspire Park is one of the few major parks that have strong local integration along the western edge. When different levels of accessibility measures are relativized for the metric area for these urban green spaces, interesting distinctions start to emerge in the data. Since 2013, there are a few important streets that have opened like the Orbital Highway and Sabah Al-Ahmad Corridor along with the south district in Lusail City. With these new roads and the additional parks and promenades, updating the space syntax model, recalculating the accessibility measures, and the ratio to size, the results appear largely consistent between 2013 and 2019. This is mainly due to two reasons. There is only a 6 year difference the two studies. Although Doha is rapidly developing, this amount of time is not enough to have a considerable difference with regards to the urban spatial network at the metropolitan scale. It also points to the robustness of the space syntax model as an objective tool to better understand the current conditions of the urban spatial network and measure the accessibility of these parks within their urban settings.

We added Al-Waab Park to this study. It is one of the smallest mini-neighborhood parks in the city. However, it is highly integrated due to its contextual relations located between Salwa Road and AI-Waab St. which are two of the most integrated streets in the city. Similar to Al-Rayyan Park, our analysis suggests Al-Waab Parks warrants special due care in its design and planning for any future expansion because of its strategic location at the local and metropolitan scale of the network. There is land available to the north and west of the park. However, it is privately owned and currently set aside for residential land uses. 
To determine whether there is an underlying spatial logic to the locating of the parks and promenades regardless of their size, we control for size utilizing a ratio. When accessibility measures are relativized for the metric area, many interesting distinctions emerge in the data (Table 3). However, the metric area remains a strong indicator of the distribution, as some variations might simply attributable to land availability and amenity provisions in private developments.

Some of the previous findings indicate there appears to be a lack of correspondence between accessibility and metric area in some parks like Al-Rayyan Park and Porto Arabia Promenade (Tannous et al., Forthcoming). Al-Rayyan Park seems too small for its strong degree of accessibility in the urban spatial network. On the other hand, Porto Arabia Promenade appears oversized for its degree of accessibility at the macro- and micro-scale of the urban spatial network. Onaiza Park and West Bay Family Park both represent the most typical parks in the city as their values hover nearest to the mean for different measurements of integration. Other parks below 4 acres tend to possess higher values for local integration, which is unsurprising since they serve specific neighborhoods.

Table 3. The rank order of public parks, promenades, and green spaces set to a ratio based on metric area for (left) global integration, (center) local integration, and (right) integration (radius-8) where green indicates the highest (extremely accessible for its size), orange indicates the lowest (very large for its accessibility) and the thick black line indicates the mean for the sample.

\begin{tabular}{|l|c|c|c|}
\hline \multicolumn{4}{|c|}{ Decending order of Global } \\
\hline \multicolumn{1}{|c|}{ Pn/Ark Name } & Area Acres & $\begin{array}{c}\text { Global } \\
\text { rad=n }\end{array}$ & $\begin{array}{c}\text { Global/Area } \\
\text { Acres }\end{array}$ \\
\hline Waab Park & 0.8 & 1.184 & $\mathbf{1 . 5 5 9}$ \\
\hline Fereej Al Sudan Family & 1.0 & 1.389 & $\mathbf{1 . 3 8 9}$ \\
\hline Al-Nuaiga family (South) & 0.9 & 1.139 & $\mathbf{1 . 2 6 6}$ \\
\hline Al-Nuaiga family & 1.0 & 1.028 & $\mathbf{1 . 0 2 8}$ \\
\hline Al-Mamoura Garden & 1.7 & 1.272 & $\mathbf{0 . 7 4 8}$ \\
\hline Bu Samra & 2.4 & 1.522 & $\mathbf{0 . 6 3 4}$ \\
\hline New Al Salata & 1.8 & 1.115 & $\mathbf{0 . 6 2 0}$ \\
\hline Gharafa Family & 1.7 & 1.032 & $\mathbf{0 . 6 0 7}$ \\
\hline Al-Khulaifat & 2.3 & 1.100 & $\mathbf{0 . 4 7 8}$ \\
\hline Onaiza Park & 2.4 & 0.846 & $\mathbf{0 . 3 5 3}$ \\
\hline West Bay Family Park & 4.0 & 1.071 & $\mathbf{0 . 2 6 8}$ \\
\hline Ceremonial Green Spine & 5.9 & 1.467 & $\mathbf{0 . 2 4 9}$ \\
\hline Zone 66 & 4.2 & 0.924 & $\mathbf{0 . 2 2 0}$ \\
\hline Park 65 & 5.5 & 1.019 & $\mathbf{0 . 1 8 5}$ \\
\hline Al-Salata & 6.2 & 1.106 & $\mathbf{0 . 1 7 8}$ \\
\hline Old Airport Park & 6.8 & 1.202 & $\mathbf{0 . 1 7 7}$ \\
\hline Pearl Park & 5.1 & 0.647 & $\mathbf{0 . 1 2 7}$ \\
\hline Souq Waqif & 10.1 & 1.259 & $\mathbf{0 . 1 2 5}$ \\
\hline Katara Promenade & 8.2 & 0.758 & $\mathbf{0 . 0 9 2}$ \\
\hline Al-Rayyan & 24.2 & 1.488 & $\mathbf{0 . 0 6 1}$ \\
\hline Dahl Al-Hamam & 21.6 & 1.275 & $\mathbf{0 . 0 5 9}$ \\
\hline Viva Bahria & 10.9 & 0.552 & $\mathbf{0 . 0 5 1}$ \\
\hline Sheraton & 22.9 & 0.990 & $\mathbf{0 . 0 4 3}$ \\
\hline Oxygen & 31.3 & 0.989 & $\mathbf{0 . 0 3 2}$ \\
\hline Pearl Green Strip & 19.3 & 0.605 & $\mathbf{0 . 0 3 1}$ \\
\hline Lusaail & 33.5 & 0.976 & $\mathbf{0 . 0 2 9}$ \\
\hline Porto Arabia & 28.0 & 0.552 & $\mathbf{0 . 0 2 0}$ \\
\hline Al-Corniche & 57.2 & 1.114 & $\mathbf{0 . 0 1 9}$ \\
\hline Katara North & 65.4 & 0.877 & $\mathbf{0 . 0 1 3}$ \\
\hline MIA & 7.5 & 0.939 & $\mathbf{0 . 0 1 3}$ \\
\hline Katara Green Hills & 74.3 & 0.972 & $\mathbf{0 . 0 1 3}$ \\
\hline Asipire & 185.7 & 1.496 & $\mathbf{0 . 0 0 8}$ \\
\hline Bidda & 426.0 & 1.282 & $\mathbf{0 . 0 0 3}$ \\
\hline AVERAGE & $\mathbf{3 4 . 6}$ & $\mathbf{1 . 0 6 6}$ & $\mathbf{0 . 3 2 4}$ \\
\hline & & & \\
\hline
\end{tabular}

\begin{tabular}{|l|c|c|c|}
\hline \multicolumn{4}{|c|}{ Decending order of Local Intg R3/Area } \\
\hline \multicolumn{1}{|c|}{ Park Name } & Area Acres & $\begin{array}{c}\text { Local Intg. } \\
\text { rad=3 }\end{array}$ & $\begin{array}{c}\text { Local } \\
\text { Intg./Area } \\
\text { Acres }\end{array}$ \\
\hline Al-Nuaiga family (South) & 0.9 & 2.503 & $\mathbf{2 . 7 8 2}$ \\
\hline Fereej Al Sudan Family & 1.0 & 2.603 & $\mathbf{2 . 6 0 3}$ \\
\hline Waab Park & 0.8 & 1.484 & $\mathbf{1 . 9 5 2}$ \\
\hline Al-Nuaiga family & 1.0 & 1.489 & $\mathbf{1 . 4 8 9}$ \\
\hline Gharafa Family & 1.7 & 2.491 & $\mathbf{1 . 4 6 5}$ \\
\hline Al-Mamoura Garden & 1.7 & 2.100 & $\mathbf{1 . 2 3 5}$ \\
\hline Bu Samra & 2.4 & 2.624 & $\mathbf{1 . 0 9 3}$ \\
\hline New Al Salata & 1.8 & 1.295 & $\mathbf{0 . 7 1 9}$ \\
\hline West Bay Family Park & 4.0 & 2.339 & $\mathbf{0 . 5 8 5}$ \\
\hline Zone 66 & 4.2 & 2.216 & $\mathbf{0 . 5 2 8}$ \\
\hline Onaiza Park & 2.4 & 1.200 & $\mathbf{0 . 5 0 0}$ \\
\hline Ceremonial Green Spine & 5.9 & 2.847 & $\mathbf{0 . 4 8 3}$ \\
\hline Al-Salata & 6.2 & 2.895 & $\mathbf{0 . 4 6 7}$ \\
\hline Old Airport Park & 6.8 & 3.105 & $\mathbf{0 . 4 5 7}$ \\
\hline Park 65 & 5.5 & 2.238 & $\mathbf{0 . 4 0 7}$ \\
\hline Al-Khulaifat & 2.3 & 0.887 & $\mathbf{0 . 3 8 6}$ \\
\hline Pearl Park & 5.1 & 1.776 & $\mathbf{0 . 3 4 8}$ \\
\hline Souq Waqif & 10.1 & 3.087 & $\mathbf{0 . 3 0 6}$ \\
\hline Katara Promenade & 8.2 & 1.389 & $\mathbf{0 . 1 6 9}$ \\
\hline Dahl Al-Hamam & 21.6 & 2.978 & $\mathbf{0 . 1 3 8}$ \\
\hline Al-Rayyan & 24.2 & 2.941 & $\mathbf{0 . 1 2 2}$ \\
\hline Sheraton & 22.9 & 2.292 & $\mathbf{0 . 1 0 0}$ \\
\hline Viva Bahria & 10.9 & 1.083 & $\mathbf{0 . 0 9 9}$ \\
\hline Pearl Green Strip & 19.3 & 1.599 & $\mathbf{0 . 0 8 3}$ \\
\hline Lusaail & 33.5 & 1.714 & $\mathbf{0 . 0 5 1}$ \\
\hline Oxygen & 31.3 & 1.500 & $\mathbf{0 . 0 4 8}$ \\
\hline Porto Arabia & 28.0 & 1.083 & $\mathbf{0 . 0 3 9}$ \\
\hline Al-Corniche & 57.2 & 2.179 & $\mathbf{0 . 0 3 8}$ \\
\hline Katara Green Hills & 74.3 & 2.199 & $\mathbf{0 . 0 3 0}$ \\
\hline MIA & 70.5 & 1.973 & $\mathbf{0 . 0 2 8}$ \\
\hline Katara North & 65.4 & 1.807 & $\mathbf{0 . 0 2 8}$ \\
\hline Asipire & 185.7 & 3.256 & $\mathbf{0 . 0 1 8}$ \\
\hline Bidda & 426.0 & 2.578 & $\mathbf{0 . 0 0 6}$ \\
\hline AVERAGE & $\mathbf{3 4 . 6}$ & $\mathbf{2 . 1 1 4}$ & $\mathbf{0 . 5 7 0}$ \\
\hline
\end{tabular}

\begin{tabular}{|l|c|c|c|}
\hline \multicolumn{4}{|c|}{ Decending order of Local Intg R8/Area } \\
\hline \multicolumn{1}{|c|}{ Park Name } & Area Acres & $\begin{array}{c}\text { Integration } \\
\text { rad=8 }\end{array}$ & $\begin{array}{c}\text { Integration/ } \\
\text { Area Acres }\end{array}$ \\
\hline Waab Park & 0.8 & 1.595 & $\mathbf{2 . 0 9 9}$ \\
\hline Fereej Al Sudan Family & 1.0 & 1.845 & $\mathbf{1 . 8 4 5}$ \\
\hline Al-Nuaiga family (South) & 0.9 & 1.629 & $\mathbf{1 . 8 1 0}$ \\
\hline Al-Nuaiga family & 1.0 & 1.370 & $\mathbf{1 . 3 7 0}$ \\
\hline Al-Mamoura Garden & 1.7 & 1.685 & $\mathbf{0 . 9 9 1}$ \\
\hline Gharafa Family & 1.7 & 1.389 & $\mathbf{0 . 8 1 7}$ \\
\hline Bu Samra & 2.4 & 1.951 & $\mathbf{0 . 8 1 3}$ \\
\hline New Al Salata & 1.8 & 1.409 & $\mathbf{0 . 7 8 3}$ \\
\hline Al-Khulaifat & 2.3 & 1.294 & $\mathbf{0 . 5 6 3}$ \\
\hline Onaiza Park & 2.4 & 1.175 & $\mathbf{0 . 4 8 9}$ \\
\hline West Bay Family Park & 4.0 & 1.532 & $\mathbf{0 . 3 8 3}$ \\
\hline Zone 66 & 4.2 & 1.345 & $\mathbf{0 . 3 2 0}$ \\
\hline Ceremonial Green Spine & 5.9 & 1.599 & $\mathbf{0 . 2 7 1}$ \\
\hline Park 65 & 5.5 & 1.487 & $\mathbf{0 . 2 7 0}$ \\
\hline OId Airport Park & 6.8 & 1.787 & $\mathbf{0 . 2 6 3}$ \\
\hline Al-Salata & 6.2 & 1.577 & $\mathbf{0 . 2 5 4}$ \\
\hline Pearl Park & 5.1 & 1.090 & $\mathbf{0 . 2 1 4}$ \\
\hline Souq Waqif & 10.1 & 1.704 & $\mathbf{0 . 1 6 9}$ \\
\hline Katara Promenade & 8.2 & 0.959 & $\mathbf{0 . 1 1 7}$ \\
\hline Dahl Al-Hamam & 21.6 & 1.802 & $\mathbf{0 . 0 8 3}$ \\
\hline Al-Rayyan & 24.2 & 1.877 & $\mathbf{0 . 0 7 8}$ \\
\hline Viva Bahria & 10.9 & 0.826 & $\mathbf{0 . 0 7 6}$ \\
\hline Sheraton & 22.9 & 1.413 & $\mathbf{0 . 0 6 2}$ \\
\hline Pearl Green Strip & 19.3 & 1.006 & $\mathbf{0 . 0 5 2}$ \\
\hline Lusaail & 33.5 & 1.231 & $\mathbf{0 . 0 3 7}$ \\
\hline Oxygen & 31.3 & 1.115 & $\mathbf{0 . 0 3 6}$ \\
\hline Porto Arabia & 28.0 & 0.826 & $\mathbf{0 . 0 3 0}$ \\
\hline Al-Corniche & 57.2 & 1.480 & $\mathbf{0 . 0 2 6}$ \\
\hline Katara Green Hills & 74.3 & 1.433 & $\mathbf{0 . 0 1 9}$ \\
\hline Katara North & 65.4 & 1.247 & $\mathbf{0 . 0 1 9}$ \\
\hline MIA & 70.5 & 1.223 & $\mathbf{0 . 0 1 7}$ \\
\hline Asipire & 185.7 & 2.007 & $\mathbf{0 . 0 1 1}$ \\
\hline Bidda & 426.0 & 1.668 & $\mathbf{0 . 0 0 4}$ \\
\hline AVERAGE & $\mathbf{3 4 . 6}$ & $\mathbf{1 . 4 4 2}$ & $\mathbf{0 . 4 3 6}$ \\
\hline
\end{tabular}

\section{Discussion and implications}

With the recently-opened Qatar Rail Metro System, public entities and researchers can utilize the methodology and findings of this research study to evaluate the viability of locations for different green urban spaces in the city of Doha. A pedestrian shed of a 400 meter radius walking distance from each Doha metro station employs the general assumption that this is a reasonable distance for a typical pedestrian to walk comfortably, given the hard desert climatic conditions in Qatar (Wakenshawy and Bunn, 2015). There are ten parks and promenades accessible within the bounds of pedestrian shed radii from the Doha Metro stations - three only marginally so at their perimeter - out of the total thirty-three parks in this study or only $30 \%$ of the sample. These parks mostly include metropolitan and regional parks 
such as Al Bidda Park from two stations (Al Bidda Station and Al Corniche Station), the north and southern parks in Katara from two stations (Qassar Station and Katara Station) but not the Katara promenade itself. Finally, it also includes Aspire Park via Azizya Station. However, several neighborhoods of Doha lack access to green parks and recreational area entirely. It requires citizens to travel via vehicles or the Doha Metro to access the large regional and national parks such Aspire Park or Al Bidda Park. Further research in this area might consider the effect of the new Doha Metro lines and stations in potentially promoting the access to more park and promenade spaces.

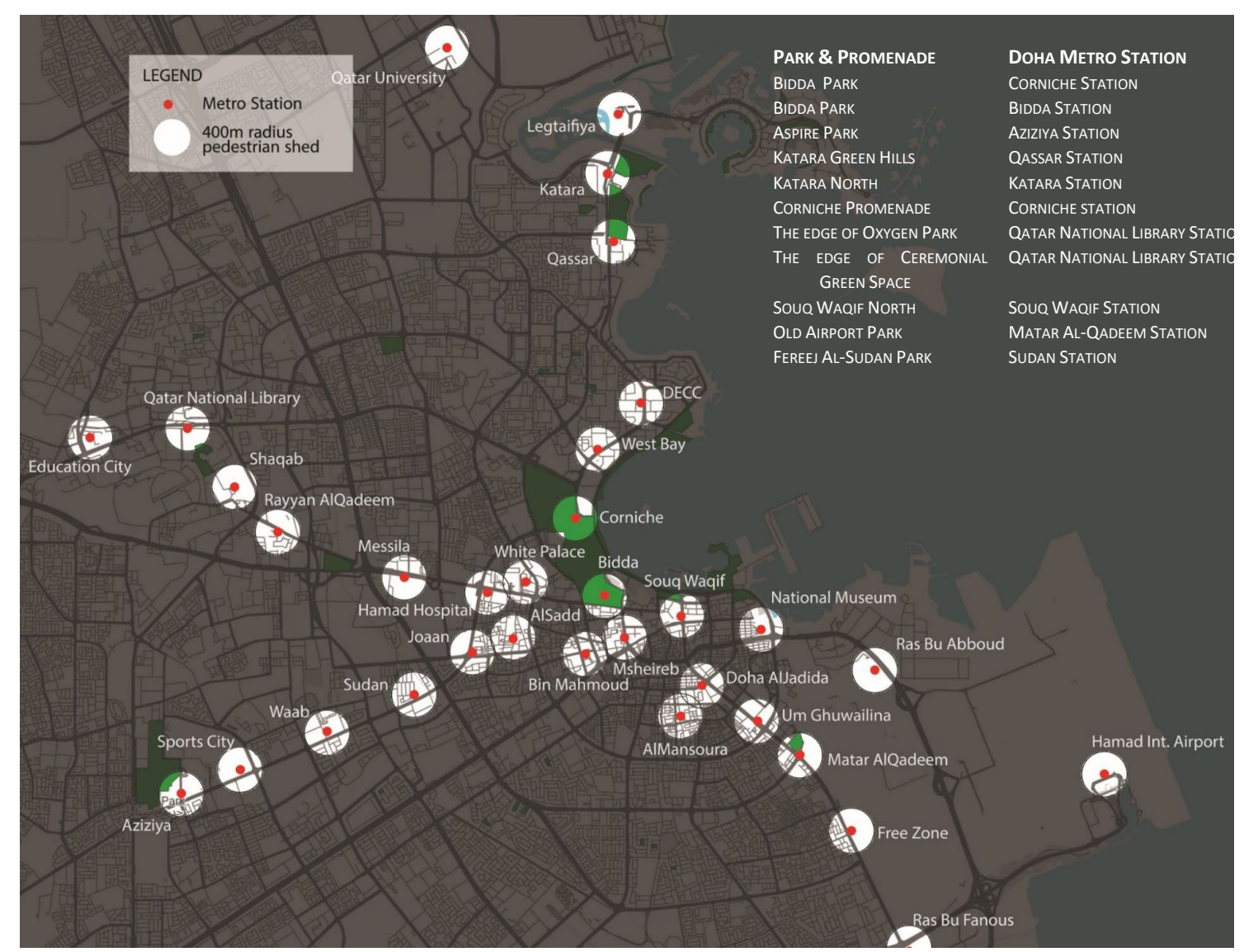

Figure 9. Pedestrian shed of a 5-minute walk (i.e., 400m radius) from the Doha Metro stations.

\section{CONCLUSION}

In a hot and dry desert environment like the city of Doha, outdoor public green spaces provide important relief for users. They are also important for enhancing social interaction and the aesthetic values of the society as well as contributing to the general health and welfare of the users and citizens. This paper focused on morphological analysis for the accessibility and size of public parks and promenades in Metropolitan Doha via the application of space syntax modeling. The methodology developed and applied in this study can assist the ministries, municipalities, and other concerned agencies and entities of the State of Qatar to objectively select the most optimal locations and assess the appropriate sizing of public urban green spaces in service to their citizens. When strategically located for their degree of accessibility within the urban spatial network, these public facilities and infrastructure have the potential to bring the greatest benefit to the greatest number of residents and visitors. The paper came to several conclusions based on this analysis. The first concerns a morphological design outcome and the second, about the planning process itself. The findings indicate there is distinctive spatial and social logic to the 
physical and spatial characteristics of urban green spaces above a certain size (regional and metropolitan) in terms of metric area in Metropolitan Doha. In contrast, these characteristics for smaller urban green spaces (neighborhood and mini-neighborhood) tend to be random. This appears to be primarily due to land availability and the nature of amenity provision (or lack thereof) in private developments. Moreover, some public parks perform better for their size and degree of accessibility than others within their local, regional, and national contexts. The analytical assessment outlined in the research study also demonstrates that land-use efficiency and open space distribution do not have to be mutually exclusive, but tailored to provide more effectively for urban life and vitality based on quality of design instead of mere allocation for the quantity of space.

\section{Acknowledgments:}

Portions of this research associated with the space syntax modeling of Metropolitan Doha; State of Qatar were supported by internal grants of Qatar University (Grant ID: QUSD-CENG-2018/2019-4 and QUCGCENG-20/21-1).

\section{References:}

Amano, T. \& Butt, I. P., K. (2018). The importance of green spaces to public health: a multi-continental analysis, Ecological Applications.

Anguluri, R. \& Narayanan, P. (2017). Role of green space in urban opening: Outlook towards smart cities. Urban Forestry \& Urban Greening, 25, 58-65.

Beatley, T. (2000). Green Urbanism: Learning from Europen Cities, Washington, D.C., Island Press.

Box, J. \& Harrison, C. (1993). Natural spaces in urban places. Town and Country Planning, 62, 231-235.

Campos, M. B. (Year) Published. All that Meets the Eye: Overlapping Isovists as a Tool for Understanding Preferable Location of Static People in Public Squares. Second International Space Syntax Symposium Proceedings (Eds. F. de Holanda, L. Amorim, F. Dufaux), 1, 20.01-20.10., 1999.

Dumper, M. R. T. \& Stanley, B. E. (2007). Cities of the Middle East and North Africa: A Historical Encyclopedia, United States of America, ABC-CLIO.

Gehl, J. (2010). Cities for People, London, Islan Press.

Gehl, J. (2011). Life Between Buildings: Using Public Space, Washington, D.C., Island Press.

Gehl, J. \& Svarre, B. (2013). How to Study Public Life, Washington, Island Press.

General Secretariat for Development Planning 2008. Qatar National Vision 2030. Doha, Qatar: Qatar Ministry of Municipality and Environment.

Hanson, J. (1989). Order and Structure in Urban Design: the plans for the rebuilding of London after the Great Fire of 1666, Ekistics.

Harrison, C., Burgess, J., Millward, A. \& Dawe, G. (1995). Accessible natural greenspace in towns and cities: A review of appropriate size and distance criteria. , Peterborough, English Nature.

Hashem, N. (2015). Assessing spatial equality of urban green spaces provision: a case study of Greater Doha in Qatar. Local Environment, 20, 386-399.

Hillier, B. (1996a). Cities as Movement Economies. Urban Design International, 1, 41-60.

Hillier, B. (1996b). Space is the Machine: A Configurational Theory of Architecture, Cambridge, Cambridge University Press.

Hillier, B., Burdett, R., Peponis, J. \& Penn, A. (1987). Creating live: or, does architecture determine anything? Architecture and Behaviour, 3, 233-250

Hillier, B., Grajewski, T., Jianming, X. \& Jones, L. (1989). The Spatial Pattern of Crime on the Studley, London Estate Unit for Architectural Studies, University College.

Hillier, B. \& Hanson, J. (1984). The Social Logic of Space, Cambridge, Cambridge University Press.

Hillier, B., Hanson, J., Peponis, J., Hudson, J. \& Burdett, R. (1983). Space syntax: a new urban perspective. Architects Journal, 178, 48-63.

Hillier, B., Penn, A., Hanson, J., Grajewski, T. \& Xu, J. (1993). Natural Movement: or, Configuration and Attraction in Urban Pedestrian Movement. Environment and Planning B: Planning and Design, 29-66. 
Hillier, B. \& Vaughan, L. (2007). The City as One Thing. Progress in Planning, 67, 205-230.

Indraganti, M. \& Boussaa, D. (2018). An adaptive relationship of thermal comfort for the Gulf Cooperation Council Countries: The case of offices in Qatar. Energy and Buildings, 159.

Jacobs, J. (1961). The Death and Life of Great American Cities, Harmondsworth, Middlesex, England, Penguin Books.

Koohsari, M. J., Kaczynski, A. T., Mcormack, G. R. \& Sugiyama, T. (2014). Using Space Syntax to Assess the Built Environment for Physical Activity: Applications to Research on Parks and Public Open Spaces. Leisure Sciences, 36, 206-216.

Lee, A. C., Jordan, H. C. \& Horsley, J. (2015). Value of urban green spaces in promoting healthy living and wellbeing: prospects for planning. Risk Management and Healthcare Policy, 8, 131-137.

Lehmann, S. (2014). Low carbon districts: Mitigating the urban heat island with green roof infrastructure. City, Culture and Society, 5, 1-8.

Major, M. D. (2018). The Syntax of City Space: American Urban Grid, New York/ London, Routledge.

Miller, J. (1989). Growth and renewal: the Swedish model. Ekistics, 56, 56-64.

Ministry of Municipality \& Environment. (2016a). Qatar National Development Framework [Online]. Qatar: Ministry of Municipality \& Environment. [Accessed 2020].

Ministry of Municipality \& Environment. (2016b). Successful Experience on "Saving Irrigation Water for Parks by 50\% [Online]. Doha, Qatar. Available: http://www.mme.gov.qa/ [Accessed Feb 2 2020].

Mirincheva, V. (Year) Published. Shifting centralities in search of identity: The new 'Heart of Doha'. Tenth International Space Syntax Symposium Proceedings, 2015 London. University College London, 1-14.

Mitchell, R. \& Popham, F. (2007). Greenspaces, urbanity and health: relationships in England. Journal of Epidemiology and Community Health, 61, 681-683.

Ottensmann, J. \& Greg, L. (2008). A use-based measure of accessibility to linear features to predict urban trail use. Journal of Transport and Land Use, Summer 2008, 1, 41-63.

Penn, A., Hillier, B., Banister, D. \& Xu, J. (1998). Configurational Modeling of Urban Movement Networks. Environment and Planning B: Planning and Design, 25, 59-84.

Peponis, J., Hadjinikolaou, E., Livieratos, C. \& Fatouros, D. A. (1989). The spatial core of urban culture. Ekistics, 56, 43-55.

Peponis, J., Zimring, C. \& Choi, Y. K. (1990). Finding the building in wayfinding. Environment and Behavior, 22, 555-590

Sahebgharani, A., Haghshenas, H. \& Mohammadi, M. (2019). A Markovian measure for evaluating accessibility to urban opportunities. Journal of Transport and Land Use, 12, 19-43.

Salama, A. \& Wiedmann, F. (2013a). Demystifying Doha: On Architecture and Urbanism in an Emerging City, London and New York, Routledge.

Salama, A. M. \& Wiedmann, F. (2013b). Evolving Urbanism of Cities on the Arabian Peninsula. Open House International, 38.

Stanners, D. \& Bourdeau, P. (1995). Europe's Environment: The Dobris Assessment, Copenhagen, European Environment Agency.

Strauss, J. \& Miranda-Moreno (2013). Spatial modeling of bicycle activity at signalized intersections. Journal of Transport and Land Use, 6, 47-58.

Tan, P. Y., Wang, J. \& Sia, A. (2013). Perspectives on five decades of the urban greening of Singapore. Ciries, 32, 24-32.

Tannous, H. (2020). Traditional Marketplaces in Context: A Comparative Study of Souq Waqif in Doha, Qatar and Souq Mutrah in Muscat, Oman. . Master of Urban Planning and Design, Qatar University.

Tannous, H., M.D., M. \& Furlan, R. (Forthcoming). Accessibility of Green Spaces in a Metropolitan Network: Using Space Syntax to Objectively Evaluate the Spatial Locations of Parks and Promenades in Doha, State of Qatar. Urban Forestry \& Urban Greening.

Tannous, H. \& Major, M. D. (Year) Published. The Spatial Logic of the Arabian Coastal City: The Case of Doha, State of Qatar and Muscat, Sultanate of Oman. 5th ISUF-Italia 2020 Conference, 2020 Rome, Italy. Sapienza Universita di Roma.

Wakenshawy, G. \& Bunn, N. 2015. How far do people walk? London: Presented at the PTRC Transport Practioner's Meeting.

Wenbo, M., Yong, W., Yingxue, Z. \& Dafang, Z. (2017). impacts of road network expansion on landscape ecological risk in a megacity, China: A case study of Beijing. Science of The Total Environmen, 574.

Whyte, W. H. (1980). The Social Life of Small Urban Spaces, New York, Project for Public Spaces. 

the Spatial Metropolitan Network of Doha, State of Qatar. 